\title{
THE INTER-TIER SPREAD OF HOUSING BUBBLES: ARE LUXURY MARKETS TO BLAME?
}

\author{
Shew-Huei KUO (Di) ${ }^{1}$, Ming-Te LEE (1) ${ }^{2}$, Ming-Long LEE (10) 3,* \\ ${ }^{1}$ Department of Finance, National Yunlin University of Science and Technology, Douliou, Yunlin, Taiwan \\ ${ }^{2}$ Department of Accounting, Ming Chuan University, Taipei, Taiwan \\ ${ }^{3}$ Department of Finance, National Dong Hwa University, Shoufeng, Hualien, Taiwan
}

Received 29 March 2020; accepted 01 September 2020

\begin{abstract}
Understanding the spread of asset bubbles is pivotal to the effectiveness of risk management. This study thus estimates housing bubbles and investigates how and to what extent price bubbles spread between the tiers of luxury and mass housing in Hong Kong. The results show that price bubbles spread between housing tiers, the spreading of bubbles is not uni-directional from luxury to mass tiers, and more than $60 \%$ of bubbles come from inter-tier spreading. Moreover, bubble shocks from the luxury tier have stronger spreading influences on the movements of bubbles in the mass housing tier than the other way around during the period before the end of the global financial crisis (GFC), whereas the opposite is true for the period after GFC. The findings are important for policy makers attempting to tackle soaring housing bubbles, financial institutions seeking to managing lending risk, and housing investors wanting to time the submarkets.
\end{abstract}

Keywords: housing bubble, housing price, luxury market, spillover, spread.

\section{Introduction}

Housing price bubbles can induce a broad misallocation of capital and resources, influence investment decisions, and have profound effects on the overall economy. Price bubbles may result from speculative transactions in markets where agents have heterogeneous opinions regarding the values of assets (Kandel \& Pearson, 1995; Morris, 1996; Hong et al., 2006) and may prevail when restrictions, such as borrowing constraints, short-sales limitations, and restriction in supply, generate market imperfections, facilitate speculative activities, and give rise to price momentum in the housing market (Haruvy \& Noussair, 2006; Mayer, 2011). Price bubbles may also be attributed to exuberant expectations of future price movements, which transmit through psychological contagion (Shiller, 2005).

Similar to the formation of price bubbles, the spread of housing price bubbles across quality tiers does not have to be associated with actual homeowner activities of trading-up or filtering-down. Psychological contagion and speculative activities can also facilitate the spread of the bubbles across quality tiers. This might be particularly possible for a geographically small and densely populated city in which informational or psychological spreading is relatively easy and starts fast from any quality tier of the housing market.

As an effort to restrain housing bubbles, governments such as those of Canada, Singapore, Taiwan, and the UK have implemented or have considered cooling measures targeting their luxury housing markets (Navaratnarajah, 2013; Taiwan Today, 2013; Ellyatt, 2014; Bourbeau \& Logan, 2016). Implicitly, the cooling policies hypothesize that housing price bubbles could spread across qualitytiered markets and that bubbles in mass housing markets come from bubbles in luxury housing markets in a uni-directional fashion. However, the relevant literature suggests that bubbles can start from any submarket, and the spread, if any, could be either from luxury markets to mass markets or in a reverse direction. Therefore, there is a clear need to conduct an empirical study on the intertier spread of housing bubbles.

Considerable work has been devoted to examine whether housing price dynamics exhibit a spatial pattern that is characterized by the spread of market disturbance from one specific region to other regions (see, inter alia, Lee et al., 2014; Tsai, 2015; Teng et al., 2017). However, few studies have been conducted to explore whether and

${ }^{*}$ Corresponding author. E-mail: ming.long.lee@gms.ndhu.edu.tw 
how housing prices spread across quality tiers. To the best of our knowledge, even such scant studies on the intertier spread of housing prices, like Coulson and McMillen (2007), Damianov and Escobari (2016), Ong and Sing (2002), Sing et al. (2006), Ho et al. (2008), and Bangura and Lee (2020), have not yet examined the inter-tier spread of housing bubbles. ${ }^{1}$

To fill the research void, this study examines how housing price bubbles spread between luxury and mass housing tiers in the geographically small and densely populated global city of Hong Kong. Specifically, this study aims to answer the following questions for the Hong Kong housing market: (1) Do housing price bubbles spread between luxury and mass housing tiers? (2) Is the spreading uni-directional from luxury to mass tiers? (3) If the spreading is not uni-directional, then are bubbles in the mass housing tier more strongly influenced by the luxury housing tier than the other way around?

This study contributes to and extends the literature on housing prices, by investigating how housing price bubbles spread from one quality tier of housing market to others. Studies on the spread of bubbles are sparse in the housing literature. To our knowledge, this is the first study to explore the inter-tier spread of housing bubbles. The findings of this research have important implications not only to policy makers responsible for regulating housing markets, both in Hong Kong and other places, but also to local and international financial institutions and investors concerning risk in the Hong Kong housing market.

\section{The Hong Kong market}

Hong Kong is a global financial hub and located on the eastern side of the Pearl River estuary in southern China. The total area of Hong Kong is only about $1.107 \mathrm{~km}^{2}$, and its population density is about 6.300 people per $\mathrm{km}^{2}$ as of 2017, making it one of the most densely populated places in the world (GovHK, 2019). Hong Kong was transferred from UK to China in 1997 and is now officially the Hong Kong Special Administrative Region (HKSAR) of the People's Republic of China under "One Country, Two Systems".

In the same year of its handover to China, the Asian financial crisis broke out and resulted in the collapse of Hong Kong's housing market (Leung \& Tang, 2012). Partly due to oversupply under the 85,000 -units plan, ${ }^{2}$ housing prices in Hong Kong plummeted consecutively until 2003, putting a sizable number of mortgaged homes in negative equity (Li, 2016a, 2016b). From March to May 2003, the

\footnotetext{
1 The studies of the inter-tier linkage of office prices conducted by Leung et al. (2008) and Lee et al. (2018) also concentrated on the spread of price movements themselves.

2 This refers to the housing development plan targeting an annual production of 85,000 housing units announced at the inauguration of Chief Executive Tung Chee-hwa in 1997 ( $\mathrm{Li}$, 2016a, 2016b). The plan was quietly shelved around the turn of the century (Li, 2016a).
}

SARS (severe acute respiratory syndrome) outbreak sent the market further into the doldrums.

From its bottom in the third quarter of 2003, Hong Kong's housing market started a robust recovery propelled by a strong, broad-based upturn in the local economy. The recovery was partially attributed to the weakening Hong Kong currency pegged to U.S. dollars, the 10 major infrastructure projects, and the supportive policies instituted by the Beijing central government (Yeung et al., 2008; Li, 2016a, 2016b; Wong, 2015). In addition, the Capital Investment Entrant Scheme was launched to allow reasonably well-off non-local people to purchase housing in Hong Kong in order to qualify for permanent citizenship (Li, 2016b). Nevertheless, the supply of residential property remained tight due to the government's strict control of land supply for new housing provision. The control was implemented, partly because of a fear over a repeat of the free falls in housing prices and strong protests for environmental concerns (Leung \& Tang, 2012; Li, 2016b).

Hong Kong housing prices plunged in the later part of 2008, when the meltdown of the U.S. subprime mortgage market turned into international financial turbulence. However, the housing market bounced back very quickly in 2009 and has been overheating ever since (Chugani, 2018). In addition to the record-low interest rate environment created by quantitative easing programs in the U.S. (Hao, 2018), mainland Chinese have been blamed for the bubble, noting the cross-border capital inflow brought by wealthy Chinese buyers that was boosted by China's own stimulus package starting in November 2008 (Global Property Guide, 2009). Others attributed the problem to the massive influx of mainlanders under various entry arrangements, ${ }^{3}$ which led to the outstripping of demand over supply (Liu, 2018).

Regarding the inter-link of bubbles, one popular view in line with the cross-border capital inflow argument is that the luxury housing tier drives the mass housing tier, as luxury properties sold to wealthy non-local people, notably mainland Chinese, at staggering prices are commonplace and receive much media attention (Lam, 2019). However, the massive mainlander inflow argument suggests another story, based on the observations that most mainlanders seeking to settle in Hong Kong are ordinary people (Ejinsight, 2018; Liu, 2018). Under this story, insufficient housing supply could arise outside the luxury tier, creating price bubbles in the mass housing tier, which then spread upward to the luxury tier.

To rein in skyrocketing housing prices, the Hong Kong government has kept rolling out cooling measures, such as lowering loan-to-value ratios, capping maximum loan amounts, and levying a special stamp duty to deter specu-

\footnotetext{
3 Under the one-way permit scheme, 150 people can move to Hong Kong from mainland China each day (Ejinsight, 2018). Under other arrangements, it is estimated that around 21,000 professionals also from mainland China could become permanent residents in Hong Kong by 2019 (Liu, 2018).
} 
lative investment and a buyer stamp duty to deter crossborder investment (O'Rahilly, 2015; Liu, 2019). These measures have been criticized for being relatively ineffective and mainly just serving to send signals to the market to cool down sentiment (Liu, 2019).

\section{Literature review}

\subsection{Asset price bubbles}

Many studies have indicated market frictions as important factors in causing price bubbles. Tirole (1982) and Allen et al. (1993) indicate that bubbles occur in a rational expectations equilibrium, in which agents are short-sale constrained and asymmetric information is present. Haruvy and Noussair (2006) and Heston et al. (2007) state that when the ability of traders to speculate over the expectation of falling prices is constrained, the influence of optimistic traders on housing prices is relatively strong. Malpezzi and Wachter (2002) and Mayer (2011) stress that, under market restrictions or a prolonged lag in supply, speculative activities over the boom and bust cycles of housing markets exert a relatively dominant influence on the volatility of housing prices and thereby may induce price bubbles.

Another view advocates that bubbles prevail in markets where agents' trading motives are influenced by psychological forces. Minsky (1974) and Kindleberger and Aliber (2011) state that optimistic market sentiment propels excessive growth of bank credit and the use of leverage among individuals and businesses, thereby giving rise to speculative frenzy and market instability. Shiller (2005) and Case and Shiller (2003) stress that a speculative bubble arises from social contagion combined with imperfect information transmission. News of price increases stirs up fervor, which heightens expectations of future price increases and spreads among market participants through social interactions. The effects of precipitating factors are amplified via a self-perpetuating excitatory feedback mechanism. Hirshleifer et al. (2011) emphasize that public opinions and behavior spread via a process influenced by psychological biases that nurture herding and information cascades.

Another approach to explain bubbles is based on models in which investors have heterogeneous beliefs and face short-sale constraints. Morris (1996) and Werner (2018) exemplify that an investor with a short-sale constraint is willing to purchase an asset at a price exceeding his assessment of the intrinsic value, in anticipation that the asset might be resold to a relatively more optimistic investor at an even higher price in the future. Harris and Raviv (1993) and Kandel and Pearson (1995) hypothesize that the differences in opinion stem from different interpretations of public announcements relevant to the determination of the intrinsic value of an asset. Scheinkman and Xiong (2003) and Hong et al. (2006) present a model of trading in which heterogeneous beliefs are induced by overconfidence.

\subsection{Housing prices, fundamentals, and bubbles}

Some studies on fundamental housing prices entail an assessment of housing affordability that associates housing prices with income. Capozza et al. (2002), Case and Shiller (2003), and McCarthy and Peach (2004) use the price-toincome ratio to evaluate whether housing is available to the typical household. Another measure of housing prices relative to fundamentals is the price-to-rent ratio. Quigley and Raphael (2004), Sinai and Souleles (2005), Campbell et al. (2011), and Ambrose et al. (2013) employ the priceto-rent benchmark to estimate whether housing markets are fairly valued. This ratio compares the costs of homeownership with the costs of renting a similar house.

Measuring owner-occupied housing costs requires consideration of both the consumption and investment factors that influence housing behavior. Dougherty and Van Order (1982), Muellbauer and Murphy (1997) and Himmelberg et al. (2005) estimate user costs of housing based on imputed rent on owner-occupied housing, expected capital appreciation in the prices of housing assets, and taxes on imputed rental income.

Housing prices also reflect distinctive features in individual markets. Davis and Palumbo (2008) and Wen and Goodman (2013) emphasize that the changes in property value are significantly affected by the proportion of the overall property value made up by the land value. Gyourko et al. (2008) and Saiz (2010) confirm that construction costs, land use regulatory environments, and geographic restrictions affect housing supply elasticity and consequently influence housing prices.

Mankiw and Weil (1989) stress that demographic fluctuations induced by changes in age composition and household disposable income affect housing demand, which in turn influences housing prices. Maennig and Dust (2008), Saiz (2007), and Gonzalez and Ortega (2013) also provide evidence for the effects of population growth on housing demand.

Housing price bubbles are unobservable. Many researchers employ the equilibrium prices derived from economic models as benchmark values with which to compare realized housing prices and determine whether housing bubbles exist (for example, Case \& Shiller, 2003; Hui \& Shen, 2006; Mayer \& Shiller, 2006; Costello et al., 2011). As Flood and Hodrick (1986) illustrate, this approach might be subject to model specification error. Luo et al. (2013) show that a framework encompassing model uncertainty induced by model misspecification can be analytically solved and mapped to a state-space representation.

Studies have made use of the state-space approach. For housing markets, Xiao and Tan (2007) employ Kalman filtering to estimate a present value model in a state-space form. In their model, price bubbles are the residual term of their measurement equation. Teng et al. (2017) estimate housing price bubbles in a state-space representation, in which the residual term is further broken down into a bubble component and a non-bubble specification error component. 


\section{Methodology and data description}

\subsection{The present-value model and housing price bubbles}

This study adopts the methods of Black et al. (2006), Costello et al. (2011), and Teng et al. (2017). We approximate a formula for the present value of housing prices using a Taylor expansion series, and utilize the approximation as a basic component for a state-space representation of housing price dynamics. ${ }^{4}$ The model is described as follows:

$$
P_{t}=E_{t} \sum_{i=1}^{\infty}\left(\frac{1}{\prod_{j=1}^{i}\left(1+\rho_{t+j}\right)}\right) D_{t+i},
$$

where: $P_{t}$ denotes the real house price at time $t ; D_{t+1}$ denotes the real rental income at time $t+1 ; \rho_{t+1}$ denotes the discount rate; $E_{t}$ denotes expectations conditional on the information set used by market participants. Equation (1) is a particular solution to the equation: $P_{t}=E\left(P_{t+1}+D_{t+1}\right) /\left(1+\rho_{t+1}\right)$ (Black et al., 2006; Teng et al., 2017).

Denote the log of $P_{t}$ and $D_{t}$ as $p_{t}$ and $d_{t}$, repectively, and the log of housing price-to-rent ratio, $\left(p_{t}-d_{t}\right)$, as $\pi_{t}$. By taking log of both sides of the equation, applying the First-order Taylor's approximation and performing repeated substitution, Black et al. (2006), Costello et al. (2011) and Teng et al. (2017) illustrate that $\pi_{t}$ can be specified as follows:

$$
\pi_{t}=\frac{k-\theta}{(1-\lambda)}+\sum_{j=0}^{\infty} \lambda^{j+1} \cdot E_{t} \Delta d_{t+j+1}-\sum_{j=0}^{\infty} \lambda^{j+1} \cdot E_{t} f_{t+j+1}
$$

where: $\Delta d_{t+j+1} \equiv d_{t+j+1}-d_{t+j} ; f_{t+j+1}$ is the time-varying real risk-free rate; $\theta$ is the constant real risk premium $^{5} ; \lambda$ and $k$ are linearization constants given by $\lambda=1 /(1+\exp (\eta))$ and $k=-\ln \lambda-(1-\lambda) \eta$ in which $\eta$ denotes the sample mean of time series $\left\{d_{t}-p_{t}\right\}$ around which the linearlization was taken.

Following Black et al. (2006), Costello et al. (2011), and Teng et al. (2017), this study estimates a three-variable vector autoregression (VAR) in $F_{t}=\left(\pi_{t}, \Delta d_{t}, f_{t}\right)$ to obtain the empirical counterparts of the forecasts for future real rent growths and risk-free rates. We then plug these forecast values into Equation (3) to generate the log of fundamental price-to-rent ratio, $\pi_{t}^{*}$.

4 For the details of the models, please refer to Costello et al. (2011) and Teng et al. (2017).

5 According to Costello et al. (2011), the real required return can be broken down into a time-varying real risk-free rate and a constant real risk premium. We use the historical premium approach of Koller et al. (2015) to estimate real risk premium for each month, where actual real returns from investing in housing market are compared to the real risk-free rate. We then calculate $\theta$ as the arithmetic average of monthly risk premium over the sample period.
The fundamental housing price, defined as the product of the fundamental price-to-rent ratio and the real rental income, can be described as:

$$
p_{t}^{f}=\pi_{t}^{*}+d_{t}
$$

where: $p_{t}^{f}$ is the logarithm of the fundamental housing price. When the possible misalignment of the housing price from the fundamental price is taken into account, we can formulate the housing price as:

$$
p_{t}=p_{t}^{f}+B_{t}+v_{t}
$$

where: $B_{t}$ denotes a price bubble; $v_{t}$ is a zero-mean, serially-uncorrelated noise. By construction, Equation (4) permits a rational bubble and a purely random deviation from the fundamental price.

The price bubble is an unobservable variable. To estimate the unobserved bubble, this study adopts the modelling framework of Teng et al. (2017), which relaxes the coefficient assumption in Equation (4) and models the housing price, fundamental price, and the bubble in a state-space form representation as:

$$
\begin{aligned}
& p_{t}=c_{1} \cdot \pi_{t}^{*}+c_{2} \cdot d_{t}+B_{t}+\zeta_{t}, \zeta_{t} \sim \text { i.i.d. } N\left(0, \sigma_{\zeta}^{2}\right) ; \\
& B_{t}=\psi \cdot B_{t-1}+v_{t}, v_{t} \sim \text { i.i.d. } N\left(0, \sigma_{v}^{2}\right),
\end{aligned}
$$

where: $\zeta_{t}$ and $v_{t}$ are serially uncorrelated errors, with $E\left(\zeta_{t}\right)=0, \operatorname{Var}\left(\zeta_{t}\right)=\sigma_{\zeta}^{2}, E\left(v_{t}\right)=0, \operatorname{Var}\left(v_{t}\right)=\sigma_{v}^{2}$, and $E\left(\zeta_{t} v_{t}\right)=0$. The inclusion of $\zeta_{t}$ and $v_{t}$ permits the housing price, $p_{t}$, and the price bubble, $B_{t}$, to be characterized as stochastic processes.

This study employs the Kalman filter algorithm and the maximum likelihood method to obtain the estimates of the parameters in the equations (Schweppe, 1965; Harvey, 1989). Kalman filtering is an efficient recursive method for producing statistical optimal estimates in the state-space model. Combined with Kalman filtering, statespace modelling permits researchers to obtain simultaneously unbiased, consistent estimates of both the model coefficients and the unobserved state variables (Harvey, 1989; Hamilton, 1994).

\subsection{Granger causality tests among bubbles}

This study conducts the causality tests in the context of a vector error correction model (VECM), in which the equation for housing tier $i$ is:

$$
\begin{aligned}
& \Delta B_{i, t}=\sum_{q=1}^{Q} \beta_{i, 1, q} \Delta B_{1, t-q}+\sum_{q=1}^{Q} \beta_{i, 2, q} \Delta B_{2, t-q}+ \\
& \ldots+\sum_{q=1}^{Q} \beta_{i, N, q} \Delta B_{N, t-q}+\alpha_{i} E C T_{t-1}+\varepsilon_{i, t},
\end{aligned}
$$

where: $\Delta$ denotes the first-difference operator; $B_{i, t}$ denotes the price bubble in housing tier $i$ at time $t$ for $i=1$, $\ldots, \mathrm{N}, E T C_{t-1}=a_{0}+a_{1} B_{1 t}+a_{2} B_{2 t}+\ldots+a_{N} B_{N t} ; \varepsilon_{i, t}$ is a white noise disturbance.

If the past values of $\Delta B_{j, t}$ contain information useful in forecasting $\Delta B_{i, t}$, where $j \neq i$, then $\Delta B_{j, t}$ Granger causes $\Delta B_{i, t}$. The Granger causality indicates that the 
changes in the bubble in housing tier $j$ lead the changes in the bubble in housing tier $i$. If the coefficients of lagged values of $\Delta B_{j, t}$ are jointly significantly different from zero, then there is evidence that price bubbles in housing tier $j$ spread to housing tier $i$ in the short run. $E C T_{t-1}$ is the last period's deviation from the long-run equilibrium relationship among the $\mathrm{N}$ housing tiers. Coefficient $\alpha_{i}$ describes the speed at which housing tier $i$ returns to equilibrium after a change in the other housing tiers. If coefficient $\alpha_{i}$ is statistically different from zero and the sign of the estimated value of $\alpha_{i}$ indicates that the bubble in housing tier $i$ adjusts towards the long-run equilibrium relationship, then the bubble in housing tier $i$ follows the long-run equilibrium relationship. As such, there is evidence for the spreading of price bubbles from other housing tiers to housing tier $i$ in the long run.

\subsection{Generalized measurement of bubble spillovers}

To assess the directions and the levels of bubble spillovers among housing tiers, this study employs the spillover measurement approach developed by Diebold and Yilmaz $(2012,2014)$. Under this framework, various aspects of spillovers are evaluated, including total spillovers, directional spillovers, and pairwise spillovers.

Denote $\gamma_{i j}^{w}(H)$ as the order-invariant, generalized forecast error variance decomposition of Pesaran and Shin (1998) at horizon $\mathrm{H}$ as below:

$$
\gamma_{i j}^{w}(H)=\frac{\sigma_{j j}^{-1} \sum_{h=0}^{H-1}\left(e_{i}^{\prime} M_{h} \Sigma e_{j}\right)^{2}}{\sum_{h=0}^{H-1}\left(e_{i}^{\prime} M_{h} \Sigma M_{h}^{\prime} e_{i}\right)}, i, j=1, \ldots, N .,
$$

where: $e_{i}$ is a unit vector, with the $i^{\text {th }}$ entry set to one and zeros elsewhere; $M_{h}$ is an $N \times N$ coefficient matrix, which multiplies the h-lagged error vector in the infinite moving average representation of an N-variable VECM model; $\Sigma$ is the covariance matrix of the error vector in VECM; $\sigma_{j j}$ is the $j^{\text {th }}$ diagonal element of $\Sigma$. The $\gamma_{i j}^{w}(H)$ evaluates the share of $\mathrm{H}$-period-ahead forecast error variation in the price bubbles of housing tier $i$ that is attributed to shocks from the price bubbles of housing tier $j$.

Since the contributions to the variances of forecast errors do not necessarily sum to unity, Diebold and Yilmaz $(2012,2014)$ standardize the variance decomposition to characterize spillovers as:

$$
\tilde{\gamma}_{i j}^{w}(H)=\frac{\gamma_{i j}^{w}(H)}{\sum_{j=1}^{N} \gamma_{i j}^{w}(H)}, i, j=1, \ldots, N,
$$

here, $\sum_{j=1}^{N} \tilde{\gamma}_{i j}^{w}(H)=1$.

Pairwise spillovers from $j$ to $i$ are measured as:

$$
C_{i \leftarrow j}(H)=\tilde{\gamma}_{i j}^{w}(H) \text {. }
$$

Net pairwise spillovers are measured as:

$$
C_{i j}(H)=\left[\frac{\tilde{\gamma}_{i j}^{w}(H)}{\sum_{k=1}^{N} \tilde{\gamma}_{i k}^{w}(H)}-\frac{\tilde{\gamma}_{j i}^{w}(H)}{\sum_{k=1}^{N} \tilde{\gamma}_{j k}^{w}(H)}\right] \times 100 .
$$

Equation (12) reflects the difference between the bubble shocks transmitted from housing tier $j$ to $i$ and the bubble shocks transmitted from housing tier $i$ to $j$.

Directional spillovers from all others to $i$ are measured as:

$$
C_{i \leftarrow \bullet}(H)=\frac{\sum_{\substack{j=1 \\ i \neq j}}^{N} \tilde{\gamma}_{i j}^{w}(H)}{\sum_{j=1}^{N} \tilde{\gamma}_{i j}^{w}(H)} \times 100 .
$$

Equation (13) measures the shares of bubble shocks received from all other housing tiers in the total error variance of price bubbles of housing tier $i$.

Total spillovers are measured as:

$$
C(H)=\frac{\sum_{\substack{i, j=1 \\ i \neq j}}^{N} \tilde{\gamma}_{i j}^{w}(H)}{\sum_{i, j=1}^{N} \tilde{\gamma}_{i j}^{w}(H)} \times 100
$$

Equation (14) measures the system-wide spillovers of price bubbles among housing tiers. It provides an overall description of the degree of system connectedness among housing tiers.

\subsection{Data description}

This study obtains data on indices of housing prices and rents in Hong Kong from the Hong Kong government and data on Hong Kong three-month Treasury bill rates from the Datastream. The data are of monthly frequency and from January 1999 to May 2017. 6 Three-month Treasury bill rates represent risk-free rates. All raw data are deflated by the Hong Kong consumer price index taken from the Datastream to obtain real indices of housing prices and rental prices as well as real T-bill rates.

Housing units are classified into tiers, in accordance with the Rating and Valuation Department, the HKSAR government. Specifically, the housing units are categorized into Tiers A, B, C, and D, with saleable area of less than 40 square meters, 40 to 69.9 square meters, 70 to 99.9 square meters, and 100 square meters or above, respectively. ${ }^{7}$ According to market practice, Tiers A to C

\footnotetext{
6 In addition to data availability, the period allows the investigation to be immune to the 1997-1998 Asian financial crisis and the 1997 handover of Hong Kong.

7 Tier D in this study merges tiers officially defined as tiers D and $\mathrm{E}$ due to low transaction volumes of tier $\mathrm{E}$ housing units in some months.
} 
are regarded as mass residential properties, and Tier D is luxury residential properties.

The Augmented Dickey-Fuller tests of unit roots indicate that the growth rates of real rental prices $\left(\Delta d_{t}\right)$, the log price-rent ratio series $\left(\pi_{t}\right)$, and the real risk-free rates $\left(f_{t}\right)$ are stationary. The results support this study to estimate a three-variable $\operatorname{VAR}\left(\pi_{t}, \Delta d_{t}, f_{t}\right)$ to obtain forecasts for real rent growths and real risk-free rates and subsequently to use the forecasts for computing the fundamental price-rent ratios.

\section{Empirical results and discussion}

\subsection{Bubbles estimated from the state-space model}

Table 1 presents the estimations of the state-space models. For all four tiers of housing, the fundamental price-to-rent ratio, $\pi_{t}^{*}$, and the rent variable, $d_{t}$, have significant, positive coefficients at or below the $5 \%$ level. The results indicate that the housing prices significantly correlate with the fundamental price-to-rent ratios and positively relate to the rental values. The coefficient of lagged bubble $B_{t-1}$, is significant in each housing tier, implying high persistence in the driving processes of bubble series. Figure 1 plots the housing price bubbles of the four housing tiers. Similar to the studies on the Australia market by Costello et al. (2011) and the Taiwan market by Teng et al. (2017), this study finds both negative and positive bubbles in Hong Kong.
Panel A of Table 2 exhibits the augmented DickeyFuller test results of the bubbles. In each tier, the test statistics for bubble-level series are not significant at any conventional level, while those for the changes of bubble series are significant at the $1 \%$ level. The results clearly show that all series of bubbles are I(1) processes. Given the unit root test results, this study proceeds to examine whether bubble series are cointegrated. Panel B of Table 2 reports Johansen's (1988) cointegration test results. Both the trace statistics and maximum eigenvalue statistics reject the null hypothesis of no cointegration at the $1 \%$ significance level. The results indicate that the price bubbles in all tiers are linked together in the long run, implying that they spread across quality-tier markets in Hong Kong in the long run.

\subsection{Granger causalities among the bubbles}

As the bubbles are cointegrated, this study constructs VECM to examine their lead-lag relationships. Table 3 presents the estimation results. In Panel A, for the equations of Tiers C and D, the error correction terms (ECTs) have statistically significant coefficients, and the signs of the ECT coefficients indicate that Tiers $\mathrm{C}$ and $\mathrm{D}$ adjust towards the long-run equilibrium relationship. These results support the existence of long-run Granger causality of bubbles from Tiers A and B to Tiers C and D. Lagged bubbles in Tier B (DBubble_B) have statistically significant coefficients in the equations of the other three tiers.

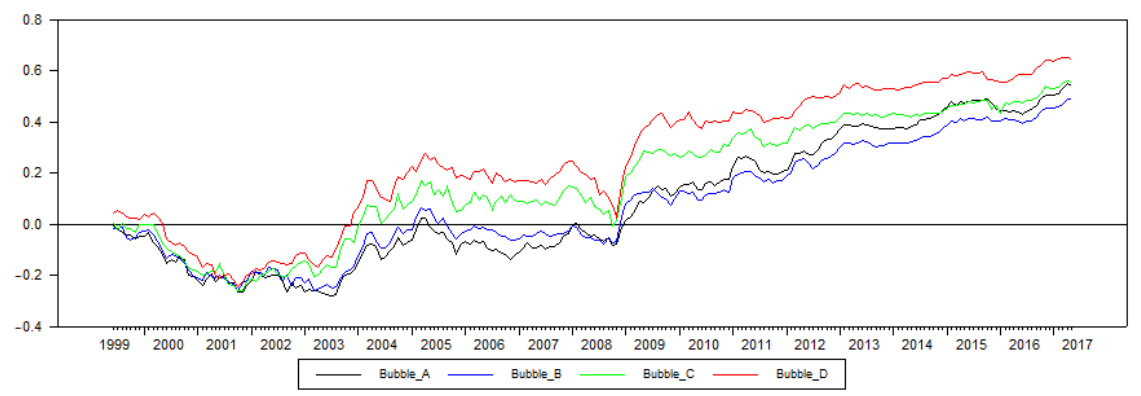

Figure 1. House price bubbles

Table 1. Estimation results of the state-space model

\begin{tabular}{|l|c|c|c|}
\hline \multicolumn{4}{|c|}{$p_{t}=c_{1} \pi_{t}^{*}+c_{2} d_{t}+B_{t}+\zeta_{t} ; B_{t}=\psi B_{t-1}+v_{t}$} \\
\hline & $c_{1}$ & $c_{2}$ & $\psi$ \\
\hline Tier A & $0.178^{* * *}$ & $1.004^{* * *}$ & $0.999^{* * *}$ \\
\hline Tier B & $0.219^{* * *}$ & $1.008^{* * *}$ & $0.994^{* * *}$ \\
\hline Tier C & $0.237^{* * *}$ & $1.001^{* * *}$ & $0.992^{* * *}$ \\
\hline Tier D & $0.177^{* *}$ & $1.000^{* * *}$ & $0.999^{* * *}$ \\
\hline
\end{tabular}

Notes: $\pi_{t}^{*}$ is the fundamental price-to-rent ratio. $p_{t}, d_{t}$, and $B_{t}$ are the log real house prices, log real rent, and price bubble, respectively.

$\zeta_{t}$ and $v_{t}$ are error terms. Consistent with Diba and Grossman (1988), Costello et al. (2011), and Teng et al. (2017), the value of parameter $\psi$ is set to be less than or equal to one so that the house prices do not contain explosive bubbles. The symbols ${ }^{* *}$ and ${ }^{* *}$ denote significance at $1 \%$ and $5 \%$ levels, respectively.
Table 2. Unit root and cointegration tests of house price bubbles

\begin{tabular}{|l|c|c|}
\hline \multicolumn{3}{|c|}{ Panel A: The augmented Dickey-Fuller test results } \\
\hline & Level & Difference \\
\hline Bubble_A & 0.451 & $-12.121^{* * *}$ \\
\hline Bubble_B & 0.299 & $-11.827^{* *}$ \\
\hline Bubble_C & 0.024 & $-13.770^{* * *}$ \\
\hline Bubble_D & -0.277 & $-11.536^{* *}$ \\
\hline
\end{tabular}

Panel B: The Johansen cointegration test results

\begin{tabular}{|l|c|c|}
\hline $\begin{array}{l}\text { Hypothesized No. } \\
\text { of CE(s) }\end{array}$ & Trace Statistic & Max-Eigen Statistic \\
\hline None & $75.015^{* *}$ & $44.181^{* * *}$ \\
\hline At most 1 & 30.834 & 18.524 \\
\hline At most 2 & 12.310 & 10.378 \\
\hline
\end{tabular}

Notes: Bubble_A, Bubble_B, Bubble_C, and Bubble_D are the house price bubbles of Tier A, Tier B, Tier C, and Tier D, respectively. No. of $\mathrm{CE}(\mathrm{s})$ denotes the number of cointegration vectors. The symbols ${ }^{* * *}$ and

** denote significance at the $1 \%$ and $5 \%$ levels, respectively. 
Table 3. The vector error correction model of house price bubbles

\begin{tabular}{|c|c|c|c|c|c|}
\hline & $\begin{array}{c}\text { Lagged } \\
\text { DBubble_A }\end{array}$ & $\begin{array}{c}\text { Lagged } \\
\text { DBubble_B }\end{array}$ & $\begin{array}{c}\text { Lagged } \\
\text { DBubble_C }\end{array}$ & $\begin{array}{c}\text { Lagged } \\
\text { DBubble_D }\end{array}$ & $\begin{array}{c}\text { Error } \\
\text { Correction term }\end{array}$ \\
\hline \multicolumn{6}{|c|}{ Panel A: For the full sample period } \\
\hline DBubble_A & -0.170 & $0.446^{* * *}$ & 0.055 & 0.022 & -0.000 \\
\hline DBubble_B & 0.153 & 0.009 & 0.077 & 0.071 & 0.000 \\
\hline DBubble_C & 0.064 & $0.457^{\star * *}$ & -0.194 & $0.193^{\star *}$ & $-0.004^{\star * *}$ \\
\hline DBubble_D & 0.080 & $0.344^{* * *}$ & 0.051 & 0.004 & $0.004^{* * *}$ \\
\hline \multicolumn{6}{|c|}{ Panel B: For the pre-GFC and GFC period } \\
\hline DBubble_A & $-0.284^{\star *}$ & $0.552^{\star * *}$ & 0.118 & 0.003 & -0.002 \\
\hline DBubble_B & 0.099 & -0.034 & 0.191 & 0.040 & $-0.004^{* *}$ \\
\hline DBubble_C & -0.044 & $0.537^{\star * *}$ & -0.062 & 0.082 & $-0.009^{* * *}$ \\
\hline DBubble_D & -0.007 & $0.397^{\star * *}$ & 0.132 & -0.009 & 0.001 \\
\hline \multicolumn{6}{|c|}{ Panel C: For the post-GFC period } \\
\hline DBubble_A & 0.023 & 0.283 & -0.031 & $0.254^{\star *}$ & -0.001 \\
\hline DBubble_B & 0.254 & -0.062 & -0.100 & 0.155 & 0.001 \\
\hline DBubble_C & $0.564^{\star * *}$ & -0.175 & $-0.450^{\star * *}$ & $0.328^{* * *}$ & $0.003^{* * *}$ \\
\hline DBubble_D & $0.384^{\star * *}$ & -0.176 & -0.039 & 0.150 & $0.006^{* * *}$ \\
\hline \multicolumn{6}{|l|}{ Chow Test for VECM } \\
\hline \multicolumn{6}{|c|}{\begin{tabular}{|ll} 
Sample Split test & 207.26 \\
\end{tabular}} \\
\hline \multicolumn{6}{|l|}{ bootstrapped p-value } \\
\hline
\end{tabular}

Notes: DBubble_A, DBubble_B, DBubble_C, and DBubble_D are the first differences in log house price bubbles of Tier A, Tier B, Tier C, and Tier D, respectively. For the full sample period, the error correction term is $2.37-13.856^{*}$ Bubble_A $+2.586^{*}$ Bubble_B $+70.168^{*}$ Bubble_C $-52.231^{*}$ Bubble_D For the pre-GFC period, the error correction term is $3.021-12.287^{*}$ Bubble_A $+7.312^{*}$ Bubble_B $+67.729^{*}$ Bubble_C $-53.039^{*}$ Bubble_D. For the post-GFC period, the error correction term is $15.200+12.362^{*}$ Bubble_A $+22.264^{*}$ Bubble_B $+1.099^{*}$ Bubble_C $-51.401^{*}$ Bubble_D. The optimal length of the lags of the vector error correction model is selected based on the Schwarz's Bayesian criterion. The symbols ${ }^{* * *}$ and ${ }^{* *}$ denote significance at $1 \%$ and $5 \%$ levels, respectively. The whole sample is also split into two sub-periods (January 1999 to November 2008; December 2008 to May 2017). Bootstrapped p-value is obtained from 100,000 bootstrapped replications.

The results imply that bubbles in Tier B Granger-cause bubbles in Tiers A, C, and D in the short run. Lagged bubbles in Tier D (DBubble_D) have a significant coefficient in the equation of Tier $C$, but not in the other equations. This result shows that bubbles in Tier D Granger-cause only bubbles in Tier $\mathrm{C}$, but not the bubbles in the other tiers in the short run.

The bursting of price bubbles in the third quarter of 2008, as shown in Figure 1, reveals a possible structural break on VECM caused by the global financial crisis (GFC). The conjecture is confirmed by the results of the sample-split Chow test for multivariate models introduced by Candelon and Lütkepohl (2001). The statistic of the test is significant at the $1 \%$ level based on 100,000 bootstrapped iterations. Consequently, we construct and report separate VECMs in Panel B for the pre-GFC and the GFC period ending in November 2008 and in Panel $C$ for the post-GFC period starting from December $2008 .^{8}$ The results show different causal relationships among housing tiers, both in the long run and the short run, for the two sub-sample periods.

For the pre-GFC and the GFC period, the coefficients of ECTs are statistically significant only in the Tier B and

\footnotetext{
8 The empirical results are qualitatively similar when the preand during GFC period ends in October 2008 and the postGFC period starts from November 2008.
}

Tier C equations. Specifically, only bubbles in Tiers B and $\mathrm{C}$ adjust back to the long-run equilibrium, and therefore the long-run Granger causality of bubbles runs from Tiers A and D to Tiers B and C. As to the short-run causality, similar results are obtained as those for the full sample period. The coefficients of lagged DBubble_B are significant in the equations for predicting bubbles in Tiers A, C, and D. However, in contrast to that for the full sample period, lagged DBubble_D does not have any significant coefficient in any equation. This result implies that bubbles in Tier D do not Granger-cause bubbles in any other tier in the short run.

For the post-GFC period, only bubbles in Tier D significantly adjust back to the long-run equilibrium, as ECT in the Tier D equation has a significant and positive coefficient. On the other hand, the significant and positive coefficient for ECT in the Tier $\mathrm{C}$ equation indicates that bubbles in Tier $\mathrm{C}$ do not adjust themselves back to the equilibrium, because in the cointegration equation from which ECT is calculated, the coefficient of Tier C is positive. The results imply that long-run causal relationships run from Tiers $A, B$, and $C$ to Tier $D$ in the post-GFC period. As to the short-run causalities, lagged bubbles in Tier A (DBubble_A) have significant coefficients in the equations of Tiers $C$ and $D$, lagged bubbles in Tier C (DBubble_C) have a significant coefficient in Tier C 
equation, and lagged bubbles in Tier D (DBubble_D) have significant coefficients in the equations of Tiers A and C.

The above VECM results indicate that the bubbles in the luxury housing tier spread to the mass housing tier in the long run before and during the GFC, but the same spreading pattern occurs only in the short run after the GFC. On the other hand, the VECM results show that the bubbles in the mass housing tier spread to the luxury housing tier in the short run before and during the GFC as well as in both the short run and the long run after the GFC. The above findings answer the first and second research questions. The results provide evidence that housing price bubbles do spread across quality tiers of housing market, and the spreading is not uni-directional from the luxury tier to the mass housing tier.

\subsection{Generalized spillover measurement of bubbles}

To further explore the dynamic inter-relationships among bubbles of different housing tiers, this study draws on the spillover measurement method of Diebold and Yilmaz $(2012,2014)$ to assess bubble spillovers. The analysis is conducted within the VECM framework with 12-step ahead forecasts. Total spillovers for the full sample period are reported in the last row of Panel A of Table 4. As revealed by the total spillover index, the system-wide spillovers of bubbles among the four tiers of housing are high. Almost $67 \%$ of price bubbles in all four housing tiers come from spillovers. This figure indicates that inter-tier spillovers of housing bubbles are substantial and deserve serious investigation.

The second last column of Panel A reports the directional bubble spillovers from others to each of the four tiers. It describes the proportion of bubble shocks received from other tiers in the total variance of the forecast error for the price bubbles of each tier. As shown from Panel A, Tier D (71.2\%) has the largest value in directional spillovers of bubbles from others, followed by Tier C (70.8\%) and Tier A (63.1\%), and Tier B (60.4\%) has the smallest. These numbers imply that Tier D is the most vulnerable to bubble shocks from the network interconnectedness of housing tiers.

The last column of the table reports the net pairwise bubble spillovers from Tier D to each of the other three tiers. It provides information about how much shocks arising in Tier D contribute to the forecast error variance of price bubbles in each of the other three tiers, in net terms. As seen from the table, the net pairwise spillovers from Tier D to Tier A, Tier B, and Tier C are $-2.3 \%,-8.5 \%$, and $-4.0 \%$, respectively. This result indicates that bubble spillovers from Tier D to Tier A, Tier B, or Tier C are smaller than that from each of the three tiers to Tier D.

Separate measurements over the pre-GFC and GFC period and the post-GFC period are reported in Panel B and Panel C, respectively. The values of total spillovers in the last rows of the two panels reveal that the four housing tiers are closely linked, with about $64-65 \%$ of the change in price bubbles being induced by the mutual impacts of

Table 4. Spillovers of price bubbles among housing tiers in percentage

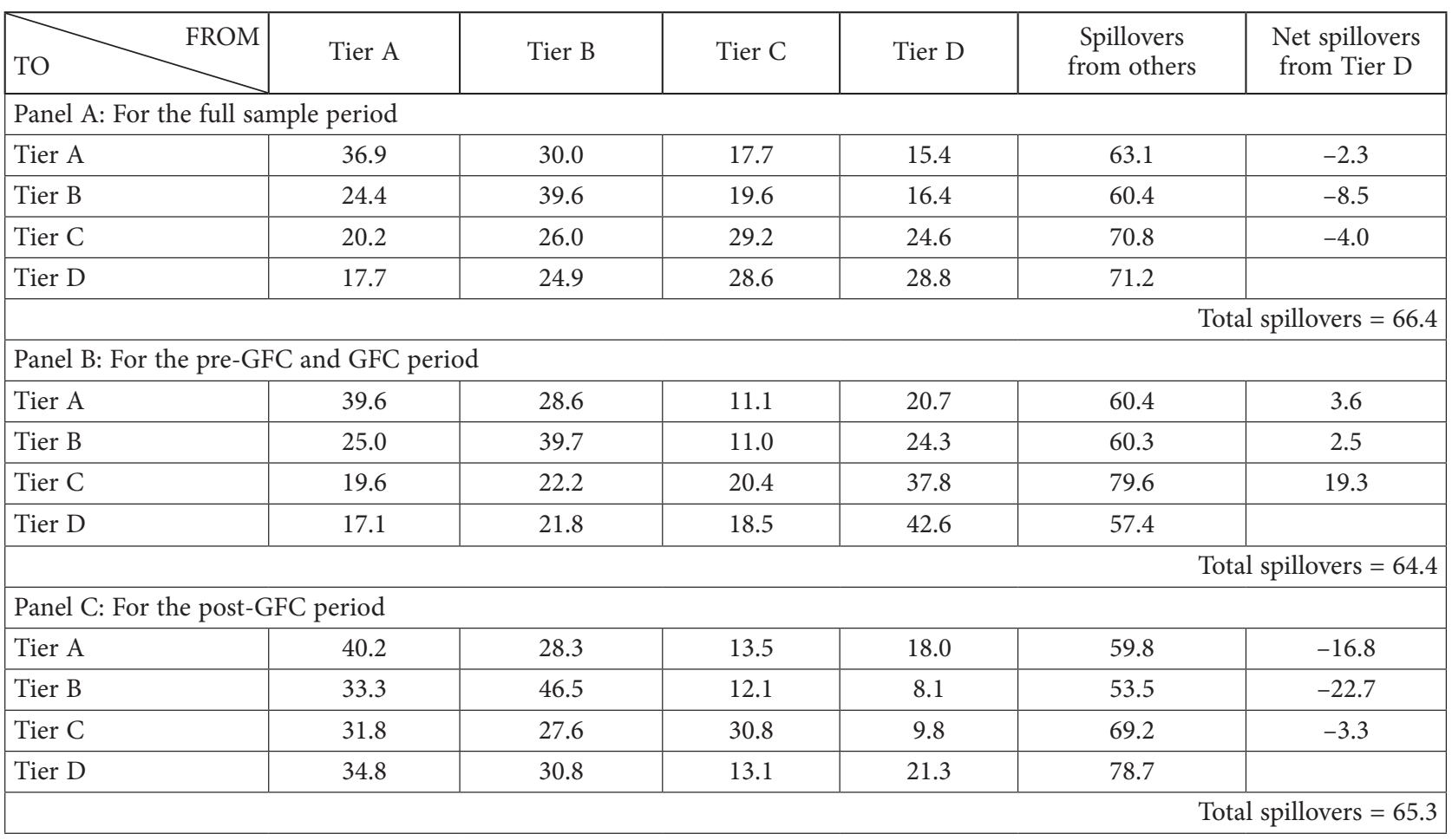

Notes: The unit of the numbers in this table is the percentage. The $i j^{\text {th }}$ entry of the upper-left $4 \times 4$ submatrix is the percentage of contribution TO the variance of 12-month-ahead forecast error of tier $i$ coming FROM shocks to tier $j$. The second farthest right column gives directional spillovers from all others to tier $i$. The rightmost column reports the values of pairwise spillovers from tier $\mathrm{D}$ to tier $i$ minus pairwise spillovers from tier $i$ to tier $\mathrm{D}$. 


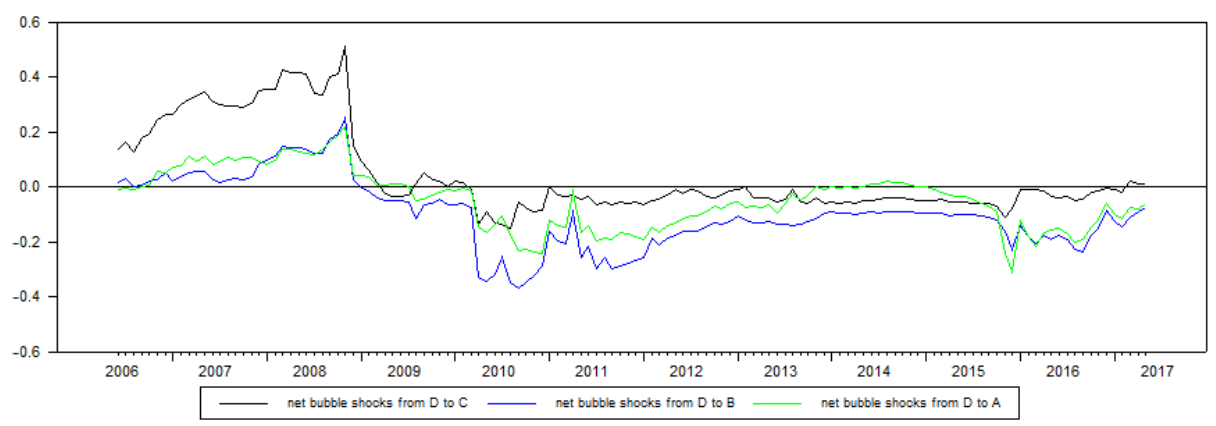

Figure 2. Net bubble spillovers from D to each of the other 3 tiers

price bubbles in the four housing tiers. More importantly, the results from the two panels indicate that the two sub-periods again exhibit distinct patterns of directional spreading of bubbles.

For the pre-GFC and GFC period, the second last column of Panel B shows that the directional spillovers of bubbles from others to Tier C are the largest (79.6\%), followed by those from others to Tier A (60.4\%), Tier B $(60.3 \%)$, and the smallest are from others to Tier D (57.4\%). In other words, before and during the GFC, Tier $\mathrm{D}$ is the least vulnerable to bubble shocks spreading from other housing tiers. The last column of the panel shows that the net pairwise spillovers from Tier D are 3.6\% to Tier A, 2.5\% to Tier B, and $19.3 \%$ to Tier C, respectively. The characteristics of these values illustrate that bubble spillovers from Tier D to Tier A, Tier B, or Tier C are larger than that from each of these three tiers to Tier D.

As shown from the second last column of Panel C, during the post-GFC period, Tier D by contrast receives the highest directional spillovers from others $(78.7 \%)$, followed by Tier C (69.2\%), Tier A (59.8\%), and Tier B (53.5\%). This result indicates that, after the GFC, Tier D becomes the most vulnerable to bubble shocks spreading from other housing tiers. The last column of Panel C shows that the net pairwise spillovers from Tier D to Tier $\mathrm{A}$, Tier $\mathrm{B}$, and Tier $\mathrm{C}$ are all negative at $-16.8 \%,-22.7 \%$, and $-3.3 \%$, respectively. These values illustrate that bubbles transmitted by Tier D to Tier A, B, or C are all smaller than those by each of these three tiers to Tier D.

The above findings yield evidence that answers the third research question. In the pre-GFC and GFC period, bubbles in the luxury housing tier have stronger spillover influences on bubbles in the mass housing tier than the other way around. However, in the post-GFC period, the opposite is true, i.e., the mass housing tier exerts stronger spillover impacts on bubbles in the luxury housing tier than vice versa.

To further confirm the above observations, this study investigates the dynamics and the continuance of the net pairwise spillovers from Tier $D$ to each of the other three tiers, using 6-year, 7-year, 8-year, and 9-year rolling sample analyses (Diebold \& Yilmaz, 2012, 2014; Gaspar, 2012). Similar results are obtained, regardless of the size of the rolling window. For brevity, only the results from
7 -year rolling samples are presented here. Figure 2 plots the time series of the net pairwise spillovers. Clearly, the magnitudes of the net spillovers vary over time. This observation provides evidence that the relative strengths of the spillovers from the luxury market to the mass housing market are time varying.

Figure 2 confirms that the patterns of bubble spillovers before and during the GFC differ from that after the GFC. The net pairwise spillover effects of Tier D on either A, $\mathrm{B}$, or $\mathrm{C}$ persist and remain positive before and during the GFC. The findings imply that the luxury tier is persistently a net transmitter of bubbles to the mass housing tier over this sub-period. However, after the GFC, the net pairwise directional spillovers from Tier D to either A, B, or C are negative most of the time. The results indicate that the luxury tier becomes a constant net receiver of bubbles from the mass housing tier during this sub-period.

\section{Conclusions}

The inter-tier spread of housing price bubbles is pivotal for the analysis of housing market risks. This study thus employs a state-space model to estimate price bubbles in housing quality tiers in Hong Kong. Based on the Granger causality test and the spillover measurement approach of Diebold and Yilmaz $(2012,2014)$, this study investigates the levels, directions, dynamics, and continuance of bubbles spreading across housing tiers.

The results of the analysis reveal a high degree of spreading of price bubbles across housing quality tiers. However, contrary to the presumption of the cooling policies targeting top-tier luxury residential properties in Canada, Singapore, Taiwan and the UK, the present study shows that the bubble spreading is not uni-directional from the luxury tier to the mass housing tier in Hong Kong.

This study also finds that the relative strengths of the spillovers from the luxury tier to the mass housing tier are time-varying in Hong Kong. Before and during the GFC, the luxury tier is persistently more influential than the mass housing tier in the transmission of bubble shocks across housing market. Bubble shocks arising in the luxury tier have greater impacts on fluctuations of price bubbles in the mass housing tier than the other way around. However, after the GFC, the patterns of spillover 
effects reverse direction. During this sub-period, the mass housing tier persistently plays a much greater role than the luxury tier in generating bubble spillovers across the housing market. Movements of price bubbles in the luxury tier are affected more strongly by shocks occurring in the mass housing tier than the opposite.

These findings have important implications. For financial institutions and housing investors, taking into account the bubble spreading patterns allows them to be able to assess more precisely the movements and the inter-tier relationships of price bubbles, manage lending risks better, and make more informed investment decisions. For government decision makers, considering the price bubble spillovers among housing tiers and the time-varying features enables them to better predict the effectiveness of housing policies aimed to address soaring housing price bubbles.

This study does not seek to identify the causes of the time-varying relative strengths of the spreading of housing bubbles. However, it worth mentioning some hypotheses about the possible causes. The findings for the pre-GFC and GFC period are consistent with the dominance of the cross-border capital inflow hypothesis. The hypothesis states that bubbles in the luxury housing tier drive bubbles in the mass housing tier, as luxury properties sold to wealthy non-local people at staggering prices are commonplace and receive much media attention. On the other hand, the findings for the post-GFC period are consistent with the argument of massive inflows of mainlanders as the main factor that exacerbates an insufficient housing supply and creates bubbles in the mass housing tier, which in turn creates bubbles in the luxury housing tier. Thus, it might be fruitful for future researchers to investigate the validity of these hypotheses.

\section{Acknowledgements}

The authors would like to thank two anonymous referees for their comments and suggestions.

\section{References}

Allen, F., Morris S., \& Postlewaite, A. (1993). Finite bubbles with short sale constraints and asymmetric information. Journal of Economic Theory, 61(2), 206-229. https://doi.org/10.1006/jeth.1993.1067

Ambrose, B. W., Eichhottz, P., \& Lindenthal, T. (2013). House prices and fundamentals: 355 years of evidence. Journal of Money Credit and Banking, 45(2-3), 477-491.

https://doi.org/10.1111/jmcb.12011

Bangura, M., \& Lee, C. L. (2020). House price diffusion of housing submarkets in greater Sydney. Housing Studies, 35(6), 1110-1141. https://doi.org/10.1080/02673037.2019.1648772

Black, A., Fraser, P., \& Hoesli, M. (2006). House prices, fundamentals and bubbles. Journal of Business Finance \& Accounting, 33(9-10), 1535-1555.

https://doi.org/10.1111/j.1468-5957.2006.00638.x

Bourbeau, J., \& Logan, N. (2016, June 3). Feds considering luxury tax to cool housing market. Global News. https://globalnews. ca/news/2738797/feds-considering-luxury-tax-on-foreignbuyers-of-multi-million-dollar-homes/
Campbell, J. Y., Giglio, S., \& Pathak, P. (2011). Forced sales and house prices. American Economic Review, 101(5), 2108-2131. https://doi.org/10.1257/aer.101.5.2108

Candelon, B., \& Lütkepohl, H. (2001). On the reliability of Chow-type tests for parameter constancy in multivariate dynamic models. Economics letters, 73(2), 155-160. https://doi.org/10.1016/S0165-1765(01)00478-5

Capozza, D. R., Hendershott, P. H., Mack, C., \& Mayer, C. J. (2002). Determinants of real house price dynamics (NBER Working Paper No. 9262). National Bureau of Economic Research. https://doi.org/10.3386/w9262

Case, K. E., \& Shiller, R. J. (2003). Is there a bubble in the housing market? Brookings Papers on Economic Activity, 34(2), 299-342. https://doi.org/10.1353/eca.2004.0004.

Chugani, M. (2018, July 19). Why Hong Kong's property bubble won't burst anytime soon. Hong Kong Economic Journal. http://www.ejinsight.com/20180718-why-hong-kong-s-property-bubble-won-t-burst-anytime-soon/

Costello, G., Fraser, P., \& Groenewold, N. (2011), House prices, non-fundamental components and interstate spillovers: the Australian experience. Journal of Banking and Finance, 35(3), 653-669. https://doi.org/10.1016/j.jbankfin.2010.07.035

Coulson, N. E., \& McMillen, D. P. (2007). The dynamics of intraurban quantile house price indexes. Urban Studies, 44(8), 1517-1537. https://doi.org/10.1080/00420980701373446

Damianov, D. S., \& Escobari, D. (2016). Long-run equilibrium shift and short-run dynamics of U.S. home price tiers during the housing bubble. Journal of Real Estate Finance and Economics, 53(1), 1-28. https://doi.org/10.1007/s11146-015-9523-2

Davis, M., \& Palumbo, M. (2008). The price of residential land in large US Cities. Journal of Urban Economics, 63(1), 352-384. https://doi.org/10.1016/j.jue.2007.02.003

Diba, B. T., \& Grossman, H. I. (1988). Explosive rational bubbles in stock prices? The American Economic Review, 78(3), 520-530. https://doi.org/10.3386/w1779

Diebold, F. X., \& Yilmaz, K. (2012). Better to give then to receive: predictive directional measurement of volatility spillovers. International Journal of Forecasting, 28(1), 57-66. https://doi.org/10.1016/j.ijforecast.2011.02.006

Diebold, F. X., \& Yilmaz, K. (2014). On the network topology of variance decompositions: measuring the connectedness of financial firms. Journal of Econometrics, 182(1), 119-134. https://doi.org/10.1016/j.jeconom.2014.04.012

Dougherty, A., \& Van Order, R. (1982). Inflation, housing costs, and the consumer price index. American Economic Review, 72(1), 154-164.

Ejinsight. (2018, October 29). Labor chief cites benefits from one-way permit scheme. Hong Kong Economic Journal. https://www.ejinsight.com/eji/article/id/1977582/20181029labor-chief-cites-benefits-from-one-way-permit-scheme

Ellyatt, H. (2014, December 4). Estate agents' anger over UK 12\% luxury homes tax. CNBC. https://www.cnbc.com/2014/12/04/ luxury-homes-tax.html

Flood, R. P., \& Hodrick, R. J. (1986). Asset price volatility, bubbles, and process switching. Journal of Finance, 41(4), 831842. https://doi.org/10.1111/j.1540-6261.1986.tb04551.x

Gaspar, R. M. (2012). Comment on 'Better to give than to receive’ by Francis X. Diebold and Kamil Yilmaz. International Journal of Forecasting, 28(1), 67-69. https://doi.org/10.1016/j.ijforecast.2011.02.009

Gonzalez, L., \& Ortega, F. (2013). Immigration and housing Booms: evidence from Spain. Journal of Regional Science, 53(1), 37-59. https://doi.org/10.1111/jors.12010 
Gyourko, J., Summers, A., \& Saiz, A. (2008). A new measure of the local regulatory environmental for housing markets. Urban Studies, 45(3), 693-729.

https://doi.org/10.1177/0042098007087341

Hao, C. (2018, November 13). Money supply holds sway in Hong Kong housing market. Hong Kong Economic Journal. http://www.ejinsight.com/20181113-money-supply-holdssway-in-hong-kong-housing-market/

Harris, M., \& Raviv, A. (1993). Differences of opinion make a horse race. Review of Financial Studies, 6(3), 473-506. https://doi.org/10.1093/rfs/5.3.473

Haruvy, E., \& Noussair, C. N. (2006). The effect of short selling on bubbles and crashes in experimental spot asset markets. Journal of Finance, 61(3), 1119-1157. https://doi.org/10.1111/j.1540-6261.2006.00868.x

Harvey, A. C. (1989). Forecasting, structural time series models and the Kalman filter. Cambridge University Press. https://doi.org/10.1017/CBO9781107049994

Heston, S. L., Lowenstein, M., \& Willard, G. A. (2007). Options and bubbles. Review of Financial Studies, 20(2), 359-390. https://doi.org/10.1093/rfs/hhl005

Himmelberg, C., Mayer, C., \& Sinai, T. (2005). Assessing high house prices: bubbles, fundamentals and misperceptions. Journal of Economic Perspectives, 19(4), 67-92. https://doi.org/10.1257/089533005775196769

Hirshleifer, D., Lim, S. S., \& Teoh, S. H. (2011). Limited investor attention and stock market misreactions to accounting information. Review of Asset Pricing Studies, 1(1), 35-73. https://doi.org/10.1093/rapstu/rar002

Ho, L. S., Ma, Y., \& Haurin, D. R. (2008). Domino effects within a housing market: the transmission of house price changes across quality tiers. Journal of Real Estate Finance and Economics, 37(4), 299-316. https://doi.org/10.1007/s11146-007-9070-6

GovHK. (2019). Hong Kong - the facts. https://www.gov.hk/en/ about/abouthk/facts.htm

Global Property Guide. (2009, November 6). Hong Kong housing bubble! Mainland buyers blame. https://www.globalpropertyguide.com/Asia/hong-kong/Price-History-Archive/HongKong-housing-bubble-Mainland-buyers-blamed-1059

Hong, H., Scheinkman, J., \& Xiong, W. (2006). Asset float and speculative bubbles. Journal of Finance, 61(3), 1073-1117. https://doi.org/10.2139/ssrn.498022

Hui, E. C. M., \& Shen, Y. (2006). Housing price bubbles in Hong Kong, Beijing and Shanghai: a comparative study. Journal of Real Estate Finance and Economics, 33(4), 299-327. https://doi.org/10.1007/s11146-006-0335-2

Kandel, E., \& Pearson, N. (1995). Differential interpretation of public signals and trade in speculative markets. Journal of Political Economy, 103(4), 831-872. https://doi.org/10.1086/262005

Kindleberger, C. P., \& Aliber, R. Z. (2011). Mania, panics, and crashes: a history of financial crises $\left(6^{\text {th }}\right.$ ed). Palgrave Macmillan.

Koller, T., Goedhart, M., \& Wessels, D. (2015). Valuation: measuring and managing the value of companies. Wiley.

Lam, K.-S. (2019). Luxury home sales in Hong Kong hit record US\$24.6 billion last year, says Centaline report. South China Morning Post. https://www.scmp.com/property/hong-kongchina/article/2183201/luxury-home-sales-hong-kong-hitrecord-us246-billion-last

Lee, M.-T., Kuo, S.-H., \& Lee, M.-L. (2018). Diffusion of Hong Kong office property prices across quality classes: ripple down or ripple up? DLSU Business \& Economics Review, 28(1), 150-165.
Lee, M.-T., Lee, M.-L., \& Lin, S.-H. (2014). Trend properties, cointegration, and diffusion of presale house prices in Taiwan: can Taipei's house prices ripple out? Habitat International, 44, 432-441. https://doi.org/10.1016/j.habitatint.2014.09.003

Leung, C. K. Y., \& Tang, E. C. H. (2012). Comparing two financial crisis: the case of Hong Kong real estate markets. In A. Bardhan, \& R. Edelstein (Eds.), Global housing markets: crises, policies and institutions (pp. 277-398). John Wiley \& Sons.

Leung, K.-Y., Cheung, W.-Y., \& Ding, E. J. (2008). Intrametropolitan office price and trading volume dynamics: evidence from Hong Kong. International Real Estate Review, 11(2), 47-74.

Li, S.-M. (2016a). Burst of the property bubble and Hong Kong's changing land and housing policies post-1997. Eurasian Geography and Economics, 57(2), 228-248. https://doi.org/10.1080/15387216.2016.1231075

Li, V. J. (2016b). Housing Policies in Hong Kong, China and the People's Republic of China (ADBI Working Paper Series No. 566). Asian Development Bank Institute. https://doi.org/10.2139/ssrn.2768070

Liu, P. (2018, July 25). Meet the 'new wave' of buyers who could keep Hong Kong's property market hot. South China Morning Post. https://www.scmp.com/property/hong-kong-china/ article/2156680/meet-new-wave-buyers-who-could-keephong-kongs-property

Liu, P. (2019). Expect more property cooling measures in Hong Kong ... but don't expect them to work, says JPMorgan. South China Moring Post. https://www.scmp.com/property/hongkong-china/article/3011561/hong-kong-government-willkeep-rolling-out-measures-tame

Luo, Y., Nie, J., \& Young, E. R. (2013). Model uncertainty, state uncertainty, and state-space models. In Y. Zeng, \& S. Wu (Eds.), State-Space models. Statistics and econometrics for finance (Vol. 1, pp. 91-112). Springer. https://doi.org/10.1007/978-1-4614-7789-1_4

Maennig, W., \& Dust, L. (2008). Shrinking and growing metropolitan areas - asymmetric real estate price reactions? The case of German single family houses. Regional Science and Urban Economics, 38(1), 63-69.

https://doi.org/10.1016/j.regsciurbeco.2007.08.009

Mankiw, N. G., \& Weil, D. N. (1989). The baby boom, the baby bust, and the housing market. Regional Science and Urban Economics, 19(2), 235-258.

https://doi.org/10.1016/0166-0462(89)90005-7

Mayer, C. (2011). Housing bubbles: a survey. Annual Review of Economics, 3, 559-577. https://doi.org/10.1146/annurev.economics.012809.103822

Mayer, C., \& Shiller, R. J. (2006). Bubble, bubble, where's the housing bubble? Comments and discussion. Brookings Papers on Economic Activity, 2006(1), 51-67. https://doi.org/10.1353/eca.2006.0018

McCarthy, J., \& Peach, R. (2004). Are home prices the next bubble? FRBNY Economic Policy Review, 10(3), 1-17. https://doi.org/10.1115/1.1667529

Minsky, H. (1974). The modeling of financial instability: an introduction [Conference presentation]. The Fifth Annual Pittsburgh Conference on Modeling and Simulation. University of Pittsburgh.

Morris, S. (1996). Speculative investor behaviour and learning. Quarterly Journal of Economics, 111(4), 1111-1133. https://doi.org/10.2307/2946709

Muellbauer, J., \& Murphy, A. (1997). Booms and bust in the UK housing market. Economic Journal, 107(445), 1701-1727. https://doi.org/10.1111/j.1468-0297.1997.tb00076.x 
Navaratnarajah, R. (2013, Feburary 27). Luxury home tax unlikely in HK: experts. PropertyGuru Limited. https://www.propertyguru.com.sg/property-management-news/2013/2/46706/ luxury-home-tax-unlikely-in-hk-experts

Ong, S.-E., \& Sing, T.-F. (2002). Price discovery between private and public housing markets. Urban Studies, 39(1), 57-67. https://doi.org/10.1080/00420980220099069

O’Rahilly, B. (2015). Hong Kong: What can it teach us about property bubbles? The Irish Times. http://www.irishtimes. com/business/commercial-property/hong-kong-what-can-itteach-us-about-property-bubbles-1.2135582

Pesaran, H. H., \& Shin, Y. (1998). Generalized impulse response analysis in linear multivariate models. Economic Letters, 58(1), 17-29. https://doi.org/10.1016/S0165-1765(97)00214-0

Quigley, J. M., \& Raphael, S. (2004). Is housing unaffordable? Why isn't it more affordable? Journal of Economic Perspectives, 18(1), 191-214. https://doi.org/10.1257/089533004773563494

Saiz, A. (2007). Immigration and housing rents in American cities. Journal of Urban Economics, 61(2), 345-371. https://doi.org/10.1016/j.jue.2006.07.004

Saiz, A. (2010). The geographic determinants of housing supply. Quarterly Journal of Economics, 125(3), 1253-1296. https://doi.org/10.1162/qjec.2010.125.3.1253

Scheinkman, J., \& Xiong, W. (2003). Overconfidence and speculative bubbles. Journal of Political Economy, 111(6), 11831219. https://doi.org/10.1086/378531

Schweppe, F. (1965). Evaluation of likelihood functions for Gaussian signals. IEEE Transactions on Information Theory, 11(1), 61-70. https://doi.org/10.1109/TIT.1965.1053737

Shiller, R. J. (2005). Irrational exuberance ( $2^{\text {nd }}$ ed.). Princeton University Press.

Sinai, T., \& Souleles, N. (2005). Owner occupied house as a hedge against rent risk. Quarterly Journal of Economics, 120(2), 763-789. https://doi.org/10.1093/qje/120.2.763
Sing, T.-F., Tsai., I., \& Chen, M.-C. (2006). Price dynamics in public and private housing markets in Singapore. Journal of Housing Economics, 15(4), 305-320. https://doi.org/10.1016/j.jhe.2006.09.006

Taiwan Today. (2013, July 28). Taiwan Luxury tax goes above and beyond. http://www.taiwantoday.tw/ ct.asp? $x$ Item $=207822 \&$ CtNode $=426$

Tirole, J. (1982). On the possibility of speculative under rational expectations. Econometrica, 50(5), 1163-1181. https://doi.org/10.2307/1911868

Tsai, I.-C. (2015). Spillover effect between the regional and the national housing markets in the UK. Regional Studies, 49(12), 1957-1976. https://doi.org/10.1080/00343404.2014.883599

Teng, H.-J., Chang, C.-O., \& Chen, M.-C. (2017). Housing bubble contagion from city centre and suburbs. Urban Studies, 54(6), 1463-1481. https://doi.org/10.1177/0042098016631297

Wen, H., \& Goodman, A. (2013). Relationship between urban land price and housing price: evidence from 21 provincial capitals in China. Habitat International, 40, 9-17. https://doi.org/10.1016/j.habitatint.2013.01.004

Werner, J. (2018). Speculative bubbles, heterogeneous beliefs, and learning (2018 Meeting Papers No. 1216). Society for Economic Dynamics.

Wong, Y. C. R. (2015). Hong Kong land for Hong Kong people: fixing the failures of our housing policy. Hong Kong University Press. https://doi.org/10.5790/hongkong/9789888208654.001.0001

Xiao, Q., \& Tan, G. K. R. (2007). Signal extraction with Kalman filter: a study of the Hong Kong property price bubbles. Urban Studies, 44(4), 865-888. https://doi.org/10.1080/00420980601185650

Yeung, Y.-M., Lee, J., \& Kee, G. (2008). Hong Kong and Macao under Chinese sovereignty. Eurasian Geography and Economics, 49(3), 304-325. https://doi.org/10.2747/1539-7216.49.3.304 